\title{
High HCV cure rates for people who use drugs treated with direct acting antiviral therapy at an urban primary care clinic
}

\author{
Brianna L. Norton ${ }^{a,}{ }^{*}$, Julia Fleming ${ }^{a}$, Marcus A. Bachhuber ${ }^{a}$, Meredith Steinman ${ }^{b}$, Joseph \\ DeLuca $^{a}$, Chinazo O. Cunningham ${ }^{a}$, Nirah Johnson ${ }^{c}$, Fabienne Laraque ${ }^{c}$, and Alain $\mathbf{H}$. \\ Litwin $^{a}$

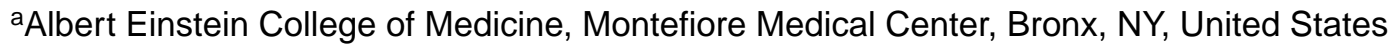 \\ bMontefiore Medical Center, Bronx, NY 10467, United States \\ 'New York City Department of Health, Viral Hepatitis Program, New York, NY, United States
}

\section{Abstract}

Background-Though direct acting antivirals (DAAs) promise high cure rates, many providers and payers remain concerned about successful treatment for people who use drugs (PWUD), even among those engaged in opioid agonist treatment (OAT). The efficacy of DAAs among PWUD in real-world settings is unclear.

Methods-We conducted a cohort study of patients initiating HCV treatment between January 2014 and August $2015(\mathrm{n}=89)$ at a primary care clinic in the Bronx, NY. Onsite HCV treatment with DAAs was performed by an HCV specialist, with support from a care coordinator funded by the NYC Department of Health. We identified four categories of drug use and drug treatment: (1) no active drug use/not receiving OAT (defined as non-PWUD); (2) no active drug use/receiving OAT; (3) active drug use/not receiving OAT; and (4) active drug use/receiving OAT. The primary outcome was SVR at 12 weeks post-treatment.

Results-Overall SVR rates were 95\% ( $n=41 / 43)$ for non-PWUD and 96\% $(n=44 / 46)$ for patients actively using drugs and/or receiving OAT $[\mathrm{p}=0.95]$. There were no differences in SVR rates by drug use or drug treatment category. Compared to non-PWUD, those with no active drug use/receiving OAT had 100\% SVR $(n=15 / 15 ; \mathrm{p}=1.0)$, those actively using drugs/not receiving OAT had 90\% SVR ( $=9 / 10 ; \mathrm{p}=0.47)$, and those actively using drugs/receiving OAT had $95 \%$ $\operatorname{SVR}(20 / 21 ; \mathrm{p}=1.0)$.

Conclusion-Regardless of active drug use or OAT, patients who received DAA therapy at an urban primary care clinic achieved high $\mathrm{HCV}$ cure rates. We found no clinical evidence to justify restricting access to $\mathrm{HCV}$ treatment for patients actively using drugs and/or receiving OAT.

*Corresponding author at: Division of General Internal Medicine, Montefiore Medical Center, 3300 Kossuth Ave Bronx, NY 10467, United States. Fax: +1 718920 5165. bnorton@montefiore.org (B.L. Norton).

Conflict of interest statement

Alain Litwin has served on the advisory board of Abbvie, BMS, Gilead Sciences, and Merck. All other authors have no conflict of interests. 


\section{Keywords}

Direct-acting antivirals (DAAs); Hepatitis C virus (HCV); Opioid agonist therapy (OAT); People who use drugs (PWUD); Real-world efficacy

\section{Introduction}

Hepatitis $\mathrm{C}$ virus (HCV) is the leading cause of end-stage liver disease and hepatocellular carcinoma in the US, and the most common indication for liver transplantation (Hernandez \& Sherman, 2011; Verna \& Brown, 2006). Without imminent action, mortality from HCVrelated disease is projected to triple over the next decade, (Davis, Alter, El-Serag, Poynard, \& Jennings, 2010; Rein et al., 2011) while HCV-related deaths have already surpassed deaths related to HIV infection (Ly et al., 2012). However, in the face of escalating morbidity and mortality, HCV treatment options have dramatically improved in recent years. New oral treatment regimens with direct-acting antivirals (DAA) result in high sustained virologic response (SVR) [cure] rates with few side effects and a short duration of therapy("Recommendations for Testing, Managing, and Treating Hepatitis C," 2017).

Despite these advances, most people who use drugs (PWUD) have not been able to access curative treatment (Alavi et al., 2013, 2014; Iversen et al., 2014; Lazarus, Sperle, Maticic, \& Wiessing, 2014; Swan et al., 2010). Although this group represents the overwhelming majority of individuals infected with HCV (Grebely \& Dore, 2014; Hagan et al., 2010; Klevens, Hu, Jiles, \& Holmberg, 2012; Nelson et al., 2011; Williams, Bell, Kuhnert, \& Alter, 2011), most have not received treatment and are categorically excluded by insurance plans, including Medicaid in many states (Barua et al., 2015). These exclusions often extend even to individuals stably engaged in substance use disorder treatment who no longer use illicit drugs, such as those receiving opioid agonist therapy (OAT) with buprenorphine or methadone. While PWUD had similar SVR rates compared to non-PWUD in a recent clinical trial of DAAs (Dore et al., 2016), provider and insurer concerns remain that PWUD and people receiving OAT will fail treatment due to nonadherence and drop-out in real world settings.

To address the gap in knowledge around real-world efficacy of DAAs in PWUD, we examined SVR rates among patients who received HCV treatment in a primary care clinic in the Bronx, NY. While previous research focuses on dichotomous categories of "non-PWUD" and "PWUD" - a heterogeneous group of patients that may be using drugs or may solely be in drug treatment - we sought to examine the impact of both drug use and engagement in drug treatment (OAT) on HCV treatment outcomes. To provide more specific data for clinicians and policymakers, we categorized patients by active drug use and OAT use and compared their characteristics and HCV treatment outcomes.

\section{Methods}

Setting

The setting is an urban primary care clinic affiliated with an academic institution (Montefiore Medical Center) located in the Bronx, NY. The clinic is a federally qualified 
health center (FQHC) offering adult primary care (including opioid agonist treatment with buprenorphine for opioid use disorder), pediatrics, obstetrics and gynecology, dentistry, mental health care, social work, nutrition, and pharmacy services onsite. The adult medicine department serves over 9000 unique patients per year. There are over $1200 \mathrm{FQHCs}$ throughout the U.S., delivering care to low-income, underserved patients at high risk for HCV (McGinn, O'Connor-Moore, Alfandre, Gardenier, \& Wisnivesky, 2008; Southern et al., 2011).

\section{Model of care}

Within adult primary care, patients receive HCV treatment from an HCV specialist - a physician trained in $\mathrm{HCV}$ care and also experienced in addiction medicine - and are supported by an HCV care coordinator. Patients with HCV antibody positivity are referred by their primary care providers or from community-based organizations (nearby syringe exchange programs) to receive an evaluation. The evaluation consists of taking a clinical history (including drug use and OAT), and HCV viral load and genotype testing, as well as a complete metabolic panel, complete blood count, noninvasive assessment of liver status (FibroSure ${ }^{\circledR}$ ), and abdominal ultrasound for those with cirrhosis. Exclusion criteria for HCV treatment included the presence of impaired renal function (defined as creatinine clearance $<30 \mathrm{~mL} / \mathrm{min}$ as calculated by the Cockcroft-Gault equation), decompensated liver disease (defined as Child Pugh Class B or C), or the presence of hepatocellular carcinoma. All patients who did not meet exclusion criteria were offered treatment. HCV visits included: initial evaluation, review of laboratory results, baseline treatment (i.e., initiation of DAA), treatment week 2 , treatment week 4 , treatment week 8 , treatment week 12 (then monthly if patients were on 24 weeks of treatment), and finally a visit to determine SVR (an undetectable viral load 12 weeks post-treatment)

In addition to office visits by an HCV specialist physician, all patients were enrolled in the Check Hep C Patient Care Coordinator Program developed and administered by the NYC Department of Health, and funded by NY City Council and private funders. This program funded a full time care coordinator to provide linkage to care, retention in care, and clinical care coordination services to assist patients to complete a full HCV medical evaluation and obtain antiviral treatment. Clinical care coordination services included a brief psychosocial assessment, provision of health education and promotion, and development and implementation of a patient navigation care plan for all patients. The care plan was tailored to the patients individual needs and could consist of: referrals for supportive services, reminders for HCV related appointments, alcohol and drug use counseling, case conferencing with the patient's care team, treatment readiness and adherence support, and processing medication prior authorization and patient assistance program applications and appeals.

\section{Patients and data collection}

Through medical record review, we identified 121 patients with an HCV evaluation (at least one visit with the onsite $\mathrm{HCV}$ treatment physician), and 89 patients initiated treatment from January 2014-August 2015, the first 16 months of the HCV care coordinator program subsequent to the Food and Drug Administration approval of sofosbuvir. HCV treatment 
initiation was defined as having been prescribed at least one HCV-specific medication (e.g., interferon, sofosbuvir, or simeprevir). We then extracted detailed information from medical records including physician notes, patients' problem lists, medication lists, prescription history, and laboratory data.

\section{Main outcome measure}

The primary endpoint was SVR (an undetectable HCV viral load 12 weeks post-treatment), which represents cure. The plasma HCV RNA was measured with the COBAS Taqman HCV/HPS v2.0 assay (Roche, Molecular Diagnostics, Pleasanton, California; lower limit of quantification $25 \mathrm{IU} / \mathrm{mL}$; limit of detection $15 \mathrm{IU} / \mathrm{mL}$ ). We analyzed this outcome with an intention-to-treat (ITT) framework, including all patients initiating treatment in this analysis. We considered patients to have virologic failure if they were lost to follow-up or did not complete the 12-week assessment.

\section{Main exposure variable: drug use}

We specifically defined four categories of drug use and drug treatment: (1) no active drug use, not receiving OAT (i.e., non-PWUD); (2) no active drug use, receiving OAT; (3) active drug use, not receiving OAT; and (4) active drug use, receiving OAT. We defined active drug use as self-reported drug use or positive urine drug screen at any point during $\mathrm{HCV}$ evaluation or treatment. Active drug use was systematically asked of all patients by their $\mathrm{HCV}$ provider; however urine toxicology screens were not universally performed. We considered urine drug screens positive if found to contain cocaine, marijuana, amphetamines. We also considered them positive if found to contain opiates, oxycodone, or methadone if a corresponding medication was not on in the prescription history or visible on the New York State Prescription Monitoring Program report. We defined receiving OAT as receiving buprenorphine or methadone for treatment for opioid use disorder (self-report or in the prescription history).

\section{Covariates}

Patient sociodemographic characteristics included: age, race, gender, and insurance type. $\mathrm{HCV}$-specific clinical characteristics included: HCV genotype, prior HCV treatment, and current $\mathrm{HCV}$ treatment regimen. Other clinical characteristics included: history of injection drug use, HIV status, cirrhosis, alcohol use, and psychiatric disorder. Cirrhosis was defined as an AST to Platelet Ratio Index (APRI) score of $\geq 1.5$ (using the patients' AST and platelet measurements upon their first HCV evaluation) or FibroSure $\geq 0.75$. Psychiatric disorder was defined as depression, anxiety, bipolar, or schizophrenia in the patient's problem list.

\section{Statistical analysis}

To examine differences between patients in each drug use category (the main exposure variable), we first compared patient characteristics in each group using chi square or Fisher exact tests for categorical variables, as appropriate, and Mann-Whitney $\mathrm{U}$ tests for continuous variables. Next, we tabulated the percentages, with $95 \%$ confidence intervals [95\% CI], of patients in each drug use category who initiated HCV treatment, completed treatment, and attended the 12-week post-treatment visit to assess SVR. Next, we compared 
SVR rates (the main outcome measure) by drug use category also using chi square or Fisher exact tests, using the "no active use, no OAT" (i.e., non-PWUD) category as the referent group. All analyses included all individuals who initiated treatment (i.e., an ITT analysis).

\section{Sensitivity analyses}

We conducted several sensitivity analyses. First, because of varying views on marijuana as active drug use, we examined SVR rates excluding patients from the active drug use category that were only using marijuana. Second, although we did not systematically document mode of active drug use (e.g., oral or injection) because we provided universal risk reduction counseling including information on safe injection practices at each visit, we examined SVR rates among those with both active drug use and a history of injection drug use.

\section{Results}

\section{Patient characteristics of those initiating treatment}

Patients were mostly male (63\%), Latino/a (54\%) or African American (39\%), with a median age of 59 years (Table 1). Nearly half had a psychiatric diagnosis (48\%) and 25\% used alcohol in the last 30 days. The majority of the patients had genotype 1 HCV (94\%) [84 with G1, 3 with G2, 1 with G3, 1 with G4], $21 \%$ were HCV treatment-experienced, $35 \%$ had cirrhosis, $24 \%$ were HIV/HCV co-infected. All patients were treated with sofosbuvircontaining regimens. Non-PWUD were treated with sofosbuvir/ledipasvir $(44 \%, \mathrm{n}=19)$, sofosbuvir/simeprevir $(26 \%, \mathrm{n}=11)$, sofosbuvir/peglyated interferon/ribavirin $(28 \%, \mathrm{n}=$ $12)$, and sofosbuvir/ribavirin $(2 \%, \mathrm{n}=1)$. Patients actively using drugs and/or receiving OAT were treated with sofosbuvir/ledipasvir $(52 \%, \mathrm{n}=24)$, sofosbuvir/simeprevir $(22 \%, \mathrm{n}=10)$, sofosbuvir/peglyated interferon/ribavirin $(20 \%, \mathrm{n}=9)$, and sofosbuvir/ribavirin $(6 \%, \mathrm{n}=3)$.

Over half (52\%) of the patients were either actively using drugs and/or receiving OAT. Of the patients actively using drugs $(\mathrm{n}=31), 61 \%(\mathrm{n}=19)$ were using opioids, $32 \%(\mathrm{n}=10)$ were using cocaine, $39 \%(\mathrm{n}=12)$ were using marijuana, and $3 \%(\mathrm{n}=1)$ were using amphetamines. Between the four drug use/OAT categories, there were significant differences in age, sex and prevalence of psychiatric disorders. Patients with active drug use were younger, with a median age of 55 (active drug use not receiving OAT) and 56 (active drug use receiving OAT) as compared to median age of 63 for patients with no active drug use not receiving OAT ( $\mathrm{p}=0.02, \mathrm{p}=0.004$, respectively). Patients with active drug use (whether receiving OAT or not) were also more likely to be male ( $88 \%$ and $90 \%$ respectively) compared to non-PWUD ( $36 \%$ male $[\mathrm{p}=0.02, \mathrm{p}=0.002])$ There were also a greater proportion of patients with a psychiatric disorder for all three groups of drug use/OAT as compared to non-PWUD (Table 2).

\section{SVR rates}

The overall HCV SVR rate was 96\% (95\% CI: 88-98\%). All patients completed therapy; treatment failures consisted of 2 viral relapses, and 2 patients lost to follow-up (Fig. 1). SVR rates were 95\% (95\% CI: 82-98\%; $\mathrm{n}=41 / 43$ ) for non-PWUD and 96\% (95\% CI: 83-99\%; $\mathrm{n}$ $=44 / 46)$ for patients actively using drugs and/or receiving OAT $(\mathrm{p}=0.95)$. There were no 
differences in SVR rates by drug use or drug treatment category. Compared to non-PWUD (SVR rate: 95\% [95\% CI: 82-98\%]), those without active drug use receiving OAT had an SVR rate of $100 \%(\mathrm{n}=15 / 15 ; \mathrm{p}=1.0)$, those with active drug use not receiving OAT had an SVR rate of $90 \%$ (95\% CI: 42-99\%; $\mathrm{n}=9 / 10 ; \mathrm{p}=0.47)$, and those with active drug use receiving OAT had an SVR rate of 95\% (95\% CI: 69-99\%; $n=20 / 21 ; p=1.0$ ). For the two patients with viral relapse, one was actively using drugs and receiving OAT, and the other person was not actively using drugs and not receiving OAT (i.e., a non-PWUD; Table 2).

\section{Sensitivity analyses}

There were a total of 6 patients with marijuana-only active drug use (4 with active drug use not receiving OAT, and 2 with active drug use receiving OAT). Excluding marijuana-only active drug use, those with active drug use not receiving OAT had an SVR rate of 100\% ( $\mathrm{n}=$ 6/6) and those with active drug use receiving OAT had an SVR rate of 95\% (95\% CI: 66-99, $\mathrm{n}=18 / 19)$. Among those with both active drug use and a history of injection drug use, SVR rates were $91 \%$ (95\% CI: $67-98 \%, n=20 / 22$ ).

\section{Discussion}

This observational cohort study provides some of the first real-world data of SVR rates for patients actively using drugs and/or receiving OAT during the era of DAAs. In a model of care-coordinator assisted $\mathrm{HCV}$ treatment at an urban primary care clinic, we found that patients, whether actively using drugs or receiving OAT, had similar SVR rates as persons who were neither using drugs nor receiving OAT. In addition to their drug or OAT use, these patients also had a significantly higher prevalence of psychiatric disorders. Though PWUD represent the majority of people affected by the HCV epidemic in the US, few PWUD have ever been treated, and many insurance plans specifically restrict access to medications for people actively using drugs as well as people receiving OAT. The findings of the current study support the broad treatment of PWUD, and policy changes that would lift medication restrictions.

Our findings are consistent with findings from other studies. Even in the arduous era of interferon, real world studies found that PWUDs initiated HCV treatment, adhered to treatment, and achieved SVR at rates similar to non-PWUDs (Bruggmann et al., 2008; Dimova et al., 2013; Melin et al., 2010). As such, national and international guidelines have explicitly advocated for the inclusion of PWUD in HCV treatment, calling for the implementation of 'treatment as prevention strategies' to reduce transmission and incident cases (Grebely et al., 2015; Hajarizadeh et al., 2016). Recently, the first clinical trial to evaluate the efficacy of once daily DAA in a population of patients on stable OST was conducted. Though all patients were receiving OAT and over half were actively using drugs, SVR rates were 95\%, similar to rates among non-PWUD in other studies (Dore et al., 2016). The current real-world study reinforces this finding, while also showing that patients actively using drugs and not receiving OAT can also do well, providing further evidence that PWUD can successfully achieve SVR using DAAs. Combined with data presented in a recent publication of this Journal, the evidence base that PWUDs can be treated successfully and achieve SVR in real-world settings is mounting. In all studies, drug use was not related 
to adherence, attendance for SVR testing, or SVR itself (Mason et al., 2017; Morris et al., 2017; Read et al., 2017).

As we seek to combat and potentially eradicate $\mathrm{HCV}$, it will be imperative to actively tackle barriers to treating PWUDs, both those stably engaged in drug treatment and those actively using drugs. In this study, we found that PWUDs, treated at an urban primary care clinic with onsite care coordination, can indeed achieve high SVR rates from DAA regimens. Other studies have also shown good HCV outcomes when patients are treated in primary care(Arora et al., 2011; Kattakuzhy et al., 2016). Community-based primary care clinics are abundant throughout the US and serve populations at high risk for HCV; some studies show an HCV prevalence rate of nearly $8 \%$ in these settings(McGinn et al., 2008; Southern et al., 2011). Strengthening HCV care at primary care clinics by incorporating care coordination could improve HCV treatment uptake and cure in PWUD. Further research to help tailor these care coordination services to individual primary care clinics could improve HCV treatment programs. Given the ease of the new, all oral HCV regimens, we have an unprecedented opportunity to treat PWUDs within medical settings that they are already accessing, that are culturally appropriate, and that can provide supportive services.

There are several limitations to this study. This study took place in one urban primary care clinic that is part of a larger academic medical center. As such, these findings may not be generalizable to all settings, particularly if funding is not available for care coordination. Furthermore, all patients were referred by their primary care providers or by a local syringe exchange, and therefore may be more motivated than persons that never reach medical care. That said, the current dearth of HCV treatment for PWUDs makes treating patients already engaged in primary care, opioid treatment, or harm reduction services a prime first target to begin reducing this epidemic. Also, this study reported SVR rates for PWUD that already initiated treatment, and there may be separate barriers to linking PWUD to care that need additional examination. This study also had a small sample size, prohibiting us from conducting multivariable analyses to examine factors associated with SVR. In addition to small sample size, the low number of failures $(n=4)$ also precluded multivariable analyses to examine specific factors associated with success or failure. Finally, due to the retrospective nature of this study, adherence data were not collected, and covariates such as psychiatric illness and drug use could be misclassified. While active drug use was systematically asked of all patients, current route of administration was not systematically documented and urine toxicology screens were not universally performed; however, given the low rate of treatment failures, misclassification of drug use would be unlikely to alter our overall findings.

\section{Conclusions}

In an urban primary care clinic, with care coordinator assisted DAA treatment provided by an HCV specialist, achievement of SVR was near universal. Rates of SVR were similarly high among all patients, regardless of active drug use or OAT. While larger real-world studies are needed, we found no clinical evidence to justify restricting access to HCV treatment for patients actively using drugs, receiving OAT, or both. 


\section{Acknowledgments}

This study was funded in part by NIDAK23DA039060, NIDAK24DA036955, and NIDAR01 DA034086.

\section{References}

Alavi M, Grebely J, Micallef M, Dunlop AJ, Balcomb AC, Day CA, Enhancing Treatment for Hepatitis C in Opioid Substitution Settings (ETHOS) Study Group. Assessment and treatment of hepatitis $\mathrm{C}$ virus infection among people who inject drugs in the opioid substitution setting: ETHOS study. Clinical Infectious Diseases. 2013; 57(Suppl. 2):S62-S69. http://dx.doi.org/10.1093/cid/ cit305. [PubMed: 23884068]

Alavi M, Raffa JD, Deans GD, Lai C, Krajden M, Dore GJ, Grebely J. Continued low uptake of treatment for hepatitis $\mathrm{C}$ virus infection in a large community-based cohort of inner city residents. Liver International. 2014; 34(8):1198-1206. http://dx.doi.org/10.1111/liv.12370. [PubMed: 24164865]

Arora S, Thornton K, Murata G, Deming P, Kalishman S, Dion D, Qualls C. Outcomes of treatment for hepatitis $\mathrm{C}$ virus infection by primary care providers. The New England Journal of Medicine. 2011; 364(23):2199-2207. http://dx.doi.org/10.1056/NEJMoa1009370. [PubMed: 21631316]

Barua S, Greenwald R, Grebely J, Dore GJ, Swan T, Taylor LE. Restrictions for medicaid reimbursement of sofosbuvir for the treatment of hepatitis $\mathrm{C}$ virus infection in the United States. Annals of Internal Medicine. 2015; 163(3):215-223. http://dx.doi.org/10.7326/M15-0406. [PubMed: 26120969]

Bruggmann P, Falcato L, Dober S, Helbling B, Keiser O, Negro F, Swiss Hepatitis C Cohort Study. Active intravenous drug use during chronic hepatitis $C$ therapy does not reduce sustained virological response rates in adherent patients. Journal of Viral Hepatitis. 2008; 15(10):747-752. http:// dx.doi.org/10.1111/j.1365-2893.2008.01010.x. [PubMed: 18637072]

Davis GL, Alter MJ, El-Serag H, Poynard T, Jennings LW. Aging of hepatitis C virus (HCV)-infected persons in the United States: A multiple cohort model of $\mathrm{HCV}$ prevalence and disease progression. Gastroenterology. 2010; 138(2):513-521. 521.e511-516. http://dx.doi.org/10.1053/j.gastro. 2009.09.067. S0016-5085(09)01885-X [pii]. [PubMed: 19861128]

Dimova RB, Zeremski M, Jacobson IM, Hagan H, Des Jarlais DC, Talal AH. Determinants of hepatitis $\mathrm{C}$ virus treatment completion and efficacy in drug users assessed by meta-analysis. Clinical Infectious Diseases. 2013; 56(6):806-816. http://dx.doi.org/10.1093/cid/cis1007. [PubMed: 23223596]

Dore GJ, Altice F, Litwin AH, Dalgard O, Gane EJ, Shibolet O, C-EDGE CO-STAR Study Group. Elbasvir-Grazoprevir to treat hepatitis $\mathrm{C}$ virus infection in persons receiving opioid agonist therapy: A randomized trial. Annals of Internal Medicine. 2016; 165(9):625-634. http://dx.doi.org/10.7326/ M16-0816. [PubMed: 27537841]

Grebely J, Dore GJ. Can hepatitis C virus infection be eradicated in people who inject drugs? Antiviral Research. 2014; 104:62-72. http://dx.doi.org/10.1016/j.antiviral.2014.01.002. [PubMed: 24468275]

Grebely J, Robaeys G, Bruggmann P, Aghemo A, Backmund M, Bruneau J, International Network for Hepatitis in Substance Users. Recommendations for the management of hepatitis $\mathrm{C}$ virus infection among people who inject drugs. International Journal of Drug Policy. 2015; 26(10):1028-1038. http://dx.doi.org/10.1016/j.drugpo.2015.07.005. [PubMed: 26282715]

Hagan H, Pouget ER, Williams IT, Garfein RL, Strathdee SA, Hudson SM, Ouellet LJ. Attribution of hepatitis $\mathrm{C}$ virus seroconversion risk in young injection drug users in 5 US cities. The Journal of Infectious Diseases. 2010; 201(3):378-385. http://dx.doi.org/10.1086/649783. [PubMed: 20053137]

Hajarizadeh B, Grebely J, Martinello M, Matthews GV, Lloyd AR, Dore GJ. Hepatitis C treatment as prevention: Evidence, feasibility, and challenges. The Lancet Gastroenterology \& Hepatology. 2016; 1(4):317-327. http://dx.doi.org/10.1016/S2468-1253(16)30075-9. [PubMed: 28404202]

Hernandez MD, Sherman KE. HIV/hepatitis C coinfection natural history and disease progression. Current Opinion in HIV and AIDS. 2011; 6(6):478-482. http://dx.doi.org/10.1097/COH. 0b013e32834bd365. [PubMed: 22001892] 
Iversen J, Grebely J, Topp L, Wand H, Dore G, Maher L. Uptake of hepatitis C treatment among people who inject drugs attending Needle and Syringe Programs in Australia, 1999-2011. Journal of Viral Hepatitis. 2014; 21(3):198-207. http://dx.doi.org/10.1111/jvh.12129. [PubMed: 24438681]

Kattakuzhy SM, Gross C, Teferi G, et al. High efficacy of HCV Treatment by primary care providers; the ASCEND study. Paper presented at the conference on retroviruses and opportunistic infections (CROI). 2016

Klevens RM, Hu DJ, Jiles R, Holmberg SD. Evolving epidemiology of hepatitis C virus in the United States. Clinical Infectious Diseases. 2012; 55(Suppl. 1):S3-S9. http://dx.doi.org/10.1093/cid/ cis393. [PubMed: 22715211]

Lazarus JV, Sperle I, Maticic M, Wiessing L. A systematic review of Hepatitis C virus treatment uptake among people who inject drugs in the European Region. BMC Infectious Diseases. 2014; 14(Suppl. 6):S16. http://dx.doi.org/10.1186/1471-2334-14-S6-S16. [PubMed: 25252742]

Ly KN, Xing J, Klevens RM, Jiles RB, Ward JW, Holmberg SD. The increasing burden of mortality from viral hepatitis in the United States between 1999 and 2007. Annals of Internal Medicine. 2012; 156(4):271-278. http://dx.doi.org/10.1059/0003-4819-156-4-201202210-00004.156/4/271 [pii]. [PubMed: 22351712]

Mason K, Dodd Z, Guyton M, Tookey P, Lettner B, Matelski J, Powis J. Understanding real-world adherence in the directly acting antiviral era: A prospective evaluation of adherence among people with a history of drug use at a community-based program in Toronto, Canada. International Journal of Drug Policy. 2017; 47:202-208. http://dx.doi.Org/10.1016/j.drugpo.2017.05.025. pii: S0955-3959(17)30129-9. [PubMed: 28619394]

McGinn T, O'Connor-Moore N, Alfandre D, Gardenier D, Wisnivesky J. Validation of a hepatitis C screening tool in primary care. Archives of Internal Medicine. 2008; 168(18):2009-2013. http:// dx.doi.org/10.1001/archinte.168.18.2009. [PubMed: 18852403]

Melin P, Chousterman M, Fontanges T, Ouzan D, Rotily M, Lang JP, CheObs Study Group. Effectiveness of chronic hepatitis $\mathrm{C}$ treatment in drug users in routine clinical practice: Results of a prospective cohort study. European Journal of Gastroenterology and Hepatology. 2010; 22(9): 1050-1057. http://dx.doi.org/10.1097/MEG.0b013e328338d9aa. [PubMed: 20351554]

Morris L, Smirnov A, Kvassay A, Leslie E, Kavanagh R, Alexander N, Najman J. Initial outcomes of integrated community-based hepatitis $\mathrm{C}$ treatment for people who inject drugs: Findings from the Queensland Injectors' Health Network. International Journal of Drug Policy. 2017; 47:216-220. http://dx.doi.org/10.1016/j.drugpo.2017.05.056. pii: S0955-3959(17)30160-3. [PubMed: 28666635]

Nelson PK, Mathers BM, Cowie B, Hagan H, Des Jarlais D, Horyniak D, Degenhardt L. Global epidemiology of hepatitis B and hepatitis $\mathrm{C}$ in people who inject drugs: Results of systematic reviews. Lancet. 2011; 378(9791):571-583. http://dx.doi.org/10.1016/S0140-6736(11)61097-0. [PubMed: 21802134]

Read P, Lothian R, Chronister K, Gilliver R, Kearley J, Dore GJ, van Beek I. Delivering direct acting antiviral therapy for hepatitis $\mathrm{C}$ to highly marginalised and current drug injecting populations in a targeted primary health care setting. International Journal of Drug Policy. 2017; 47:209-215. http://dx.doi.org/10.1016/j.drugpo.2017.05.032. pii: S0955-3959(17)30136-6. [PubMed: 28587943]

Recommendations for Testing, Managing, and Treating Hepatitis C. 2017. Retrieved July 4, 2017, from http://www.hcvguidelines.org.

Rein DB, Wittenborn JS, Weinbaum CM, Sabin M, Smith BD, Lesesne SB. Forecasting the morbidity and mortality associated with prevalent cases of pre-cirrhotic chronic hepatitis $\mathrm{C}$ in the United States. Digestive and Liver Disease. 2011; 43(1):66-72. http://dx.doi.org/10.1016/j.dld. 2010.05.006. [PubMed: 20739252]

Southern WN, Drainoni ML, Smith BD, Christiansen CL, McKee D, Gifford AL, Litwin AH. Hepatitis $\mathrm{C}$ testing practices and prevalence in a high-risk urban ambulatory care setting. Journal of Viral Hepatitis. 2011; 18(7):474-481. http://dx.doi.org/10.1111/j.1365-2893.2010.01327.x. [PubMed: 20497311]

Swan D, Long J, Carr O, Flanagan J, Irish H, Keating S, Cullen W. Barriers to and facilitators of hepatitis $\mathrm{C}$ testing, management, and treatment among current and former injecting drug users: A 
qualitative exploration. AIDS Patient Care and STDS. 2010; 24(12):753-762. http://dx.doi.org/ 10.1089/apc.2010.0142. [PubMed: 21138381]

Verna EC, Brown RS Jr. Hepatitis C virus and liver transplantation. Clinics in Liver Disease. 2006; 10(4):919-940. http://dx.doi.org/10.1016/j. cld.2006.08.012. [PubMed: 17164125]

Williams IT, Bell BP, Kuhnert W, Alter MJ. Incidence and transmission patterns of acute hepatitis C in the United States, 1982-2006. Archives of Internal Medicine. 2011; 171(3):242-248. http:// dx.doi.org/10.1001/archinternmed.2010.511. [PubMed: 21325115] 


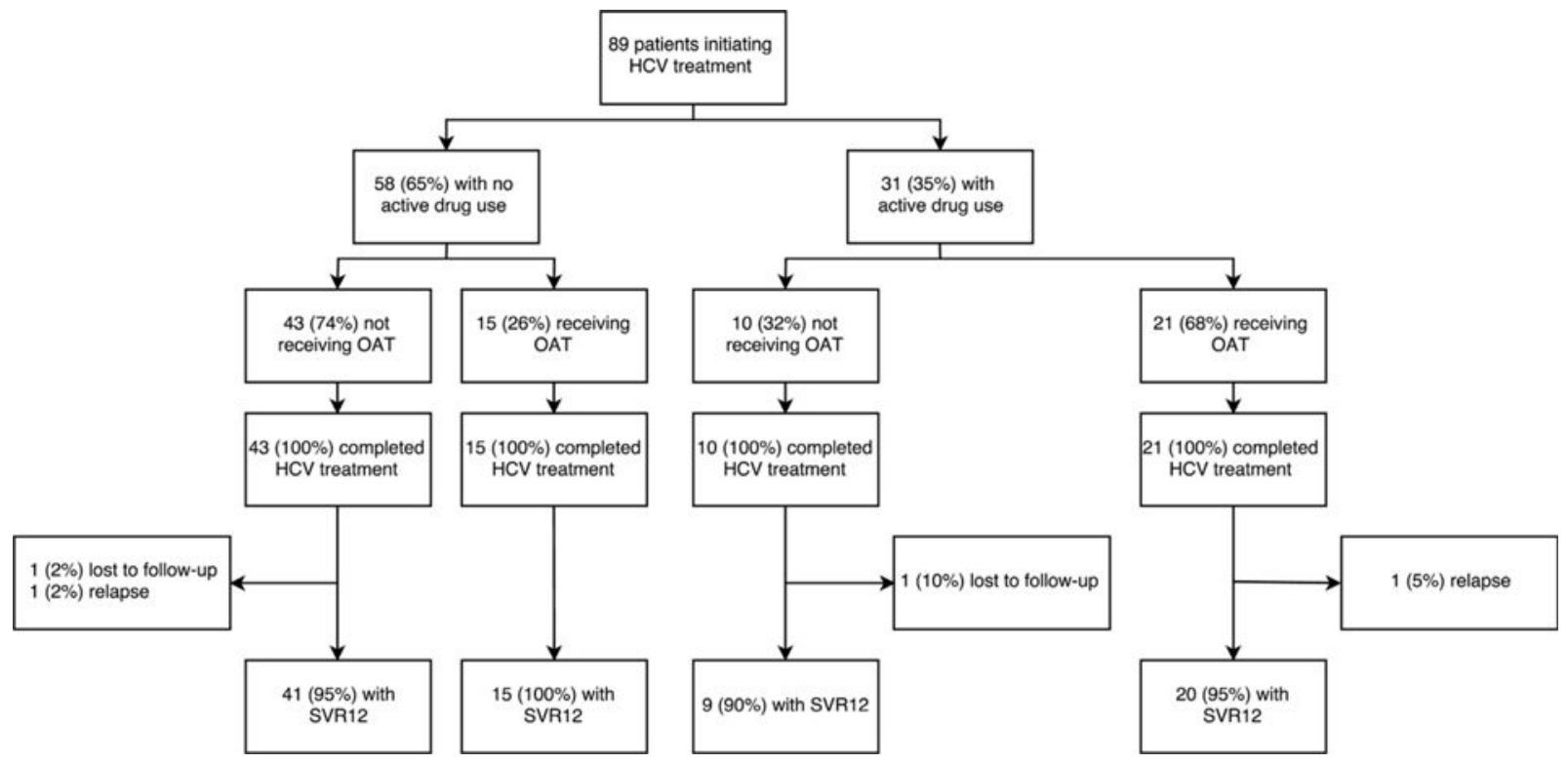

Fig. 1.

Hepatitis $\mathrm{C}$ virus SVR rates among patients initiating direct acting antiviral therapy in an urban primary care clinic, by drug use and drug treatment status. 


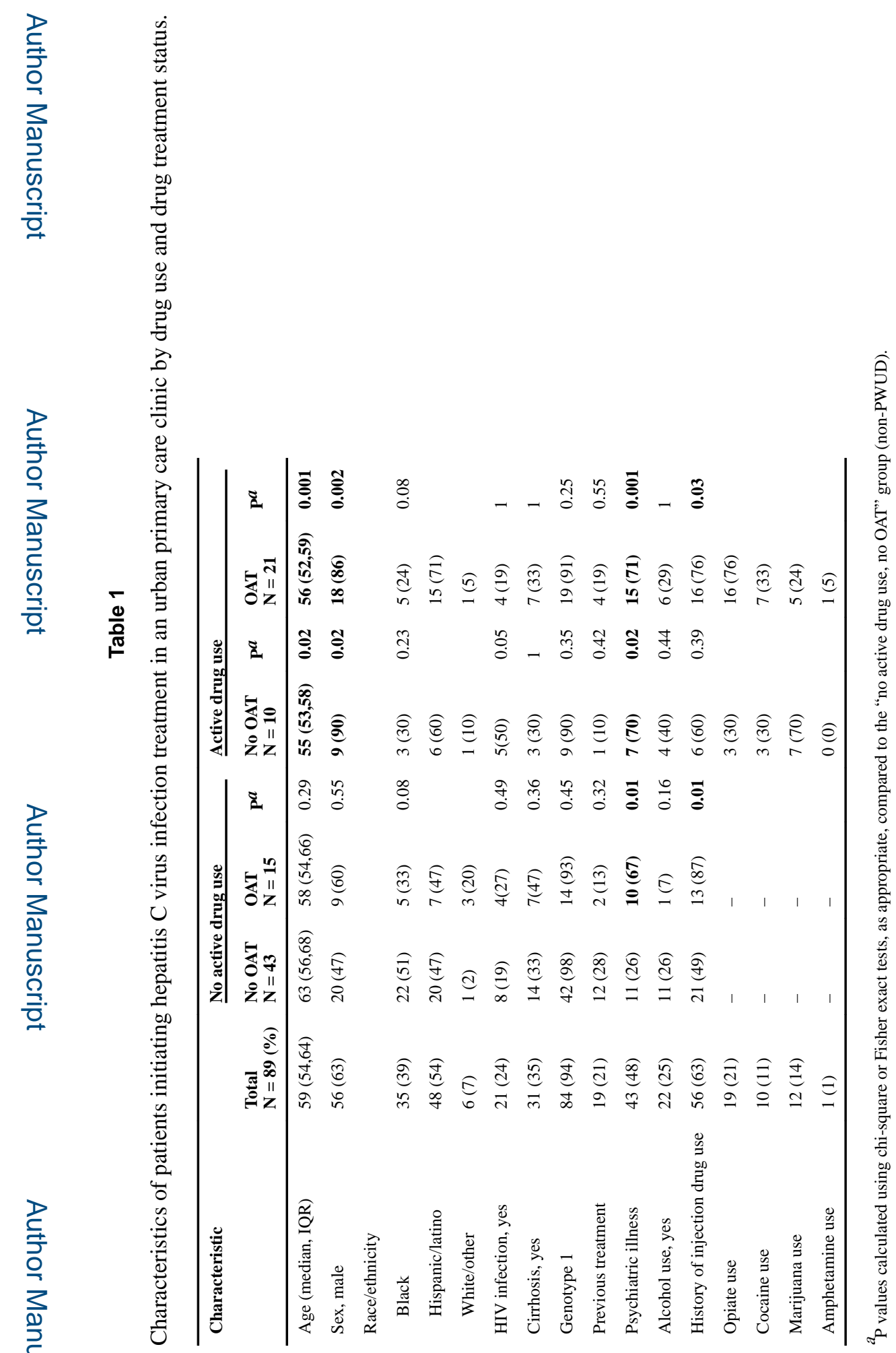




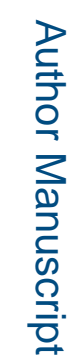

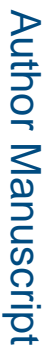

品

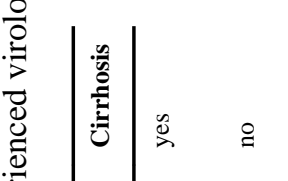

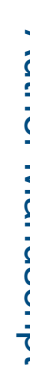

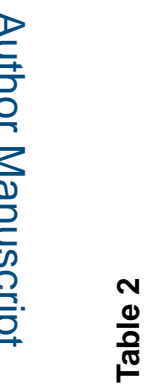

这

ख)

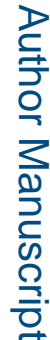

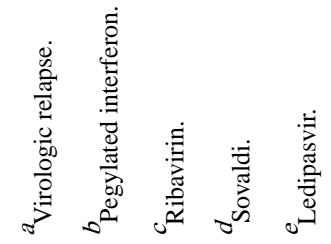

Int J Drug Policy. Author manuscript; available in PMC 2018 February 22. 